\title{
Cyber Vaticinations: A Systematic Review of Schoolchildren's Activities in the Cyberspace in Thirty Years' Time
}

\author{
Olugbenga A IGE ${ }^{1, *}$, Taiwo Grace Olulowo ${ }^{2}$, Thulebona G Shawe ${ }^{1}$ \\ ${ }^{1}$ School of Social Sciences and Language Education, University of the Free State, Republic of South Africa \\ ${ }^{2}$ Department of Social Sciences Education, Adekunle Ajasin University, Akungba Akoko, Nigeria
}

Received October 19, 2020; Revised July 28, 2021; Accepted August 22, 2021

\section{Cite This Paper in the following Citation Styles}

(a): [1] Olugbenga A IGE, Taiwo Grace Olulowo, Thulebona G Shawe, "Cyber Vaticinations: A Systematic Review of Schoolchildren's Activities in the Cyberspace in Thirty Years' Time," Universal Journal of Educational Research, Vol. 9, No. 10, pp. 1732 - 1741, 2021. DOI: 10.13189/ujer.2021.091002.

(b): Olugbenga A IGE, Taiwo Grace Olulowo, Thulebona G Shawe (2021). Cyber Vaticinations: A Systematic Review of Schoolchildren's Activities in the Cyberspace in Thirty Years' Time. Universal Journal of Educational Research, 9(10), 1732 - 1741. DOI: 10.13189/ujer.2021.091002.

Copyright $(2021$ by authors, all rights reserved. Authors agree that this article remains permanently open access under the terms of the Creative Commons Attribution License 4.0 International License

\begin{abstract}
There are scholarly pieces of evidence attesting to the use of the Internet by children in a manner comparable to adult users. Many children now use mobile phones, laptop computers, and tablet PCs that are connected to the Internet to access the cyberspace and engage in any activity of interest. The Spatio-temporal communications by schoolchildren in cyberspace have reduced television viewing which in the analog era was subjected to parental control. Unfortunately, the technical nature of the Internet makes it difficult for parents to control the contents available to schoolchildren in the cyberspace. This article uses the space transition theory to examine and analyse schoolchildren's current cyberspace activities relating to cyber dating, cybersex, cyberbullying, and online gambling to infer the dimensions that these activities would take in the next thirty years. Current scholarly articles were explicated on popular engagements of schoolchildren in the cyberspace and analysed to predict the dimensions of these activities in thirty years. This paper is of scholarly value on the vogues that would be prevalent in the cyberspace in the next generation. The emerging trends in the scholarly articles analysed were used to recommend cyber-parenting related measures on training schoolchildren in the next thirty years.
\end{abstract}

Keywords Cyber Vaticinations, Schoolchildren's Activities, Online Gambling, Cybersex, Cyber Bullying, Cyber Parenting

\section{Introduction}

In recent times, every individual is exposed to gadgets that are linked to the Internet or to a network. These gadgets include laptops, smart phones, etc. The usage of Internet facilities by schoolchildren and youth has assorted effects on them, ranging from beneficial effects such as improvement in self-worth, apparent social support, academic support, identity exploration, cross-cultural interactions, and detrimental effects like exposure to lifelike content and cyber-bullying (Best, Manktelow \& Taylor, 2014; Badmus, 2018). The manner with which things are done in recent times has changed owing to the easy access to the Internet. The Internet is used for several human activities. However, taking full advantage of the benefits and reducing the peril of Internet usage among schoolchildren and youths has become one of the prime challenges faced by parents, schools, and educational authorities. The aim of this article is to explore the current activities of schoolchildren in cyberspace, and project the nature of such activities in the next thirty years. This article discusses the future of schoolchildren's activities in the cyberspace, and recommends what teachers need to do to monitor and curb 
undesirable dimensions of these activities in the next thirty years.

\section{Theoretical Framework}

\subsection{Space Transition Theory}

Space transition theory developed because of the failure or inadequacy of traditional theories to elucidate the justification for incidence of crimes in the cyberspace (Jaishankar, 2008). This theory views the cyberspace as a new-fangled locus of scandalous or criminal activities (Jaishankar, 2008). "Space transition theory explicates the nature of the behaviour of the persons who exhibit their conforming and non-conforming behaviour in the physical and cyber space. It describes the movement of an individual from a space to another (i.e. from physical to cyber space and vice versa). The theory holds that people behave differently when they move from a space to another" (Jaishankar, 2008). The postulates of Jaishankar's (2008) theory are:

1. Persons, with repressed criminal behaviour (in the physical space) have the inclination to commit crimes in cyberspace, which, otherwise they would avoid in physical space, because of their status and position.

2. Identity flexibility, dissociative anonymity, and cyberspace's lack of deterrence provide the offenders the choice to commit crime in the cyberspace.

3. Criminal behaviour in the cyberspace may be imported to the physical space which in physical space may be exported to cyberspace as well.

4. Offenders' intermittent ventures into the cyberspace and the dynamic spatio-temporal nature of cyberspace afford them the way to escape.

5. (a) Strangers are likely to unite in the cyberspace to commit crimes in the physical space.

(b) Accomplices of physical space may unite to commit crimes in cyberspace.

6. Persons from closed society are more likely to commit crimes in the cyberspace than persons from open society.

7. The conflict of norms and values of the physical space with the norms and values of the cyberspace may lead to cybercrimes.

This theory is applicable to this study in many ways. For instance, the first relevant postulate of space transition theory is the idea of identity flexibility and dissociative anonymity. In this proposition, Jaishankar (2008) describes the behaviour of people online, as he highlights the concepts of identity flexibility and dissociative anonymity as identified by Suler (2005). According to Jaishankar (2008), anonymity has a disinhibition effect such that people would occasionally put up unpleasant needs or emotions such as bullying other people, sexualizing children and women, hurling abuses through texts and symbols. The effects of disinhibition are further manifested in people's tendency for unaverred and open discussions about personal issues that they might fear to discuss in face-to-face encounters. In that sense, anonymity is surprisingly useful for people to attain disinhibition effect. Further, he posits that when people can separate their actions from their real world and identity, it generates in them, a sense of safety from the consequences of those actions and rightly so. Whatever they do or say in anonymity cannot be directly linked to them. On venting out bitter feelings, they need not take full responsibility for those actions. And perhaps most interesting of all, people can always convince themselves that those behaviours' 'aren't me at all'. In psychological terms, this is called 'dissociation' (Suler, 2005).

Another scholarly explanation advanced by Ige (2020) on the idea of strangers teaming up in cyberspace to commit crimes in the real spaces is the possibility that learners can collude with persons not known to them in the physical space to bully and smear other users in the cyberspace. Associates of physical space are likely to unite to bully another person in the cyberspace. For instance, friends can come together in the cyberspace to bully another person that is not in their group as a way of dealing with such person. Ige (2020) observes that this postulate implies that learners can actualize acts in the physical space that might prove consequential in the cyberspace.

\section{School Children Activities in the Cyberspace}

The advent and advancement of technology have reshaped every aspect of the world from analog to digital. Also, it has influenced ways schoolchildren, teenagers and youth socialize, connect, learn, communicate, develop relationship, and interact. It enables individuals to be in their comfort zones and connect with others (Good \& Fang, 2015). Cyberspace represents the novel means of communicating via digital devices connected to the Internet. This is a rapidly outmoding traditional mode of communicating (Bryant, 2001).

Cyberspace is a trendy depiction for digital atmosphere in which Internet-oriented activities occur. It has created novel virtual spaces and communities for people to conveniently engage in diverse activities that as well take place in the physical environment since it is not linked with place and time. Cyberspace exists in many digital conduits. It is the environment learners and teachers operate when they are on call with a loved one within and outside the country. The way schoolchildren live, communicate, relate and work has been modernized by the advent of the Internet.

Cyberspace has momentous importance to educational, 
social, and political interactions amidst people and nations of the world. Also, cyberspace has numerous advantages which include provision of informational resources, instantaneous communication, social networking (great medium to connect with people from different locations within and outside one's country), job and business opportunities. Despite the colossal importance of cyberspace, access without apposite policy and utilization may result in abuse that could culminate in cyber bullying, online gambling, cybersex, cyber dating violence and other related cyber-abusive activities. Some of these are likely to characterize school children's activities in the cyberspace thirty years from now (Badmus, 2018). School children will prefer to engage in these activities over the Internet than real life because of some of its feature relating to confidentiality, accessibility, availability, anonymity, etc.

\subsection{Cyber Bullying}

Every individual has different attitudes and behaviours which can either have positive or negative effects on others. The belligerent attitudes and behaviours any person or collection of persons engages in deliberately to hurt another person are referred to as bullying (Olweus, 1993; Patchin \& Hinduja, 2006; Belsey, 2007; Smith et al., 2008; Calvete et al., 2010). Bullying perpetrators are those who have substantial advantage over others because of their wealth, position, or status, etc., (Aksaray, 2011). These actions are caused by varied reasons such as jealousy, hate, and revenge upon others (Hoff \& Mitchell, 2009; Topçu, 2014).

Technology has been described as a tool that eases human stress; it enables speed and efficacy in carrying out daily responsibilities. Despite the prevailing benefits of technology, it is not free from detrimental effects that can lead to social problems (Surry \& Farquahr, 1997). In recent years, advancement in technology and its prevalent usage by human brought about a new-fangled model of bullying known as cyber bullying (Akbaba \& Eroğlu, 2013). This model of bullying reveals itself especially via the extreme concentration of school children, teenagers, and youth particularly in online activities such as chatting and messaging (Cho \& Yoo, 2016). Corcoran, Guckin and Prentice (2015) define cyber bullying as the utilization of electronic or digital media to humiliate, harm, or harass another individual.

In cyber bullying, there is no need for physical supremacy as any person who has the intentions of hurting another person can successfully commit disruptive behaviour with the aid of the screen of inscrutability provided by technology. Technology gives room for some destructive actions (invective, abuse, verbal harassment, sharing of unauthorized personal information, etc.) that an individual might not have the courage to exhibit in real life situation. These destructive actions include posting depressing annotations regarding others, intruding the privacy of others by posting their personal information and taking charge of their online accounts for wrong purposes (Arıcak et al., 2008; Bulut \& Alc1, 2014; Calvete et al., 2010; Patchin \& Hinduja, 2006).Victims of cyber bullying are mostly affected socially, emotionally, and psychologically (Şahin, Aydin \& Sari, 2012). Scholars have observed that those victims of cyberbullying have symptoms such as fear, hopelessness, nervousness, mistrust, social angst, retribution, lack of self-worth, attempted suicide, anger, and feeling of weakness (Hoff \& Mitchell, 2009; Akbulut \& Çuhadar, 2011; Schenk \& Framouw, 2012). Lee and Chun (2020) further add that academic attainment of victims of cyber bullying is also significantly affected (See Koç et al., 2016; Schneider, O’Donnell, Stueve \& Coulter, 2012).

\subsection{Cyber Dating}

Cyber dating is another activity children are likely to fully engage in as against school dating in thirty years from now. The dawn of technology in the world has brought about lot of changes in the way many things are done, including dating. Dating has been defined as a form of social, sexual, and romantic relationship typically between two folks (Niehuis, 2008). Dating has gone beyond the traditional style in which people meet probable quixotic buddies in their everyday lives through a mutual network (e.g., a communal pal introducing two single persons to each other), a likelihood of head-to-head encounter (e.g., come close to a fresh colleague or an alien at a russet store), or mishmash of the two (e.g., conversing with a friend-of-a-friend at a social gathering) (Finkel, Eastwick, Karney, Reis \& Sprecher, 2012). The digital era has brought about cyber dating which involves searching for a quixotic partner on the Internet via a dedicated website usually with the goal of creating a romantic relationship.

Although traditional dating is an assorted type that consists of many milieus for meeting would-be buddies (e.g., meeting at a bar vs. in church), these milieus collectively vary from online dating in that they do not proffer the same structure and extent of access, communication, and matching. The scheme that allows people on the Internet to unearth and introduce themselves to prospective partners typically with the aim of building social, sexual, personal, and romantic relationships is online dating. Online dating has to do with looking for a pleasant prospective partner, initiating conversation through messaging, getting to know each other, and setting up for a meeting in person (AnKee \& Yazdanifard, 2015). This new form of dating has enabled learners to meet new pals and prospective chums on the Internet. One of the key differences between online dating and conventional dating is the sense of urgency (Slater, 2013).

Bryant and Sheldon (2017) state that cyber dating takes 
place on mobile dating applications and online dating websites. Mobile dating applications are applications that can be accessed from mobile devices such as smart phones or tablets. They are often based on locations and its usage is straightforward. In contrast, online dating websites are accessed from a laptop or desktop connected to the Internet, illustrated by detailed profiles, searching and viewing multiple dating matches, and providing users with the option to explore exact criterion (Stewart, 2015). Unlike online dating websites, mobile dating applications do not require the creation profiles as most are accessed via other social media accounts and this has given school children access to cyber dating as they are exposed to gadgets that are linked to the Internet or to a network.

Traditional dating has to do with the physical ability to go out and socialize which is the prerequisite to meeting new people but online dating has reduced the transportation cost, physical and environmental limitations which might be a hindrance to meeting new chum, thus allowing them to expand their social, romantic and personal relationship. School children will prefer online dating because of the opportunity it offers. For instance, when trying to meet new friends via another friend or in the bar, church, club is not successful, online dating provides another platform of meeting people (Vandeweerd, et al., 2016).

Online dating gives partners a sense of control over their dating lives. Any of the partners can decide to terminate the relationship created any moment if it does not work out since there would be less pressure and risk of physical reprisal unlike traditional dating (McWilliams \& Barrett, 2014: Vandeweerd et al., 2016). Unlike traditional dating, online daters tend to feel safe since the interaction takes place on dating websites or mobile applications in the cyberspace. For instance, each partner can decide to search for the profiles of their potential partners and have a glimpse of their personalities before initiating any interaction (Vandeweerd et al., 2016). It also helps partners to limit the kind of information that will be divulged and helps to avoid sharing of personal information until they are familiar to each other. These might not be possible in traditional dating as partners usually have meeting points which can be a source of getting some personal information that each partner might not want to share. With access to the Internet, adolescents now can communicate with others from anywhere without leaving their rooms.

Cyber dating provides a novel occasion for obnoxious behaviours and harassment (Baker \& Carren o, 2016). Cyber dating violence refers to abuse that occurs through digital media over the Internet. Zweig et al., (2014) state that cyber dating abuse means the control, harassment, stalking and abuse of one's dating partner through digital devices over the Internet (Zweig et al., 2014). Leisring and Giumetti, (2014) refer to cyber dating abuse as the act of monitoring, controlling, threatening, humiliating, abusing, or harassing a partner through Internet-facilitated technology. David-Ferdon and Hertz (2007) define cyber dating abuse as the use of communication technologies for instant messaging, blogging, text messaging, emailing, and social networking to control, threaten, or harass one's partner in the cyberspace.

Cyber dating abuse can crop up in a diversity of ways (Lancaster et al., 2020). This includes the use of digital media to exercise control over one's partner, and superfluous incursion of partner's private life. A good example is Lancaster et al. (2020) explanation on using social network passwords without the authorization of partners (See Borrajo et al., 2015; Burke et al., 2011; Draucker \& Martsolf, 2010; Lyndon et al., 2011; Melander, 2010; Peskin et al., 2017) and sexting (e.g., being pressured to send a sexual or nude photo of oneself; Reed, Tolman, \& Ward, 2016).

\subsection{Cybersex}

Another activity that school children might likely engage in thirty years from now is cybersex. The advent and momentous development of the Internet in the digital era and its prevalent use in daily existence in nearly all societies has hoisted meaningful deliberations in human societies. Even though the Internet might be deemed a prevailing device that affords access to an extensive array of information which consequently abets modernization and globalization, in recent times, it has developed into a place of safety where people's reveries burgeon are devoid of physical penalty (Franc, Khazaal, Jasiowka, Lepers, Bianchi-Demicheli, \& Rothen, 2018).

Franc et al. (2018) defines cybersex as the usage of Internet sexual actions which include shows of real-life sex, pornography, chat rooms or webcam. Carnes (2001) argues that whatever can be done in the actual life can also be possible online. Cybersex does not require the person involved to leave their location before there can be sexual activities. School children might be anywhere, be it classroom, home or church to engage in sexual activities depending on the level of access to the Internet, confidentiality and affordability. Young et al. (2000) in Franc et al. (2018) affirm that these characteristics will further encourage cybersex amidst school children in the future as it gives room for behind the scenes and repeated sexual interactions.

Unlike real life sex which can be controlled by parents via placing of restrictions on their wards' movement, not allowing visitors into the house whenever they are around, etc., cybersex is likely difficult to control. unless the children do not have smart phones with Internet connection: School children would predominantly engage in this form of sexual activities thirty years from now as it will give them a sort of shelter where people's fantasies thrive with little or no external interference. Psychosomatic dysfunction, emotional anguish, 
turbulence in nap and routinely life tasks are connected to extreme cybersex (See Franc et al., 2018; Grubbs et al., 2015; Tsimtsiou et al., 2014; Twohig et al., 2009).

Cybersex refers to a subset of online sexual activity (OSA) which involves at least two people conversing about sexual activities, needs and/or daydream (Shaughnessy et al. 2011b). The virtual environment offers superior confidentiality to those who engage in cybersex than physical milieu. There are moderately furtive and secured places in the virtual community in which those who engage in cybersex can meet with limited possibility of experiencing social consequences which occur in offline circumstances (Brown et al., 2005). Ross, Rosser, and Stanton (2004) describe cybersex as the process of engaging in sexual self-inspiration over the Internet with another person. Ross et al. (2000) further assert that cybersex offers an occasion to practice and fuse a character for conduct that if performed would be insecure. School children will likely engage in cybersex thirty years from now because it is easier and less aggravating. It is safer than meeting someone in real life for sex and it lessens the worry of being rejected. It is safer and transcends geographical boundaries that allow partners to be anonymous (Ross, Rosser \& Stanton, 2004). In the opinion of Döring, (2009); Wéry and Billieux (2017), cybersex includes a variety of sexual-associated activities over the Internet. Some of these include sex yak, virtual sex games and dating, pornography, and webcam.

\subsection{Cyber Gambling}

Online gambling refers to the assortment of betting activities accessible via contrivance facilitated by the Internet. They are also referred to as betting activities enabled by the advancement in technology, custodian of apparatus facilitated by Internet accessibility. Internet gambling is not a different mode of betting activity but an approach divergent from betting physically in an outlet structured for gambling. Internet gambling is a fundamentally computerized activity that can be carried out confidentially at any time and place depending on the availability of Internet enabled gadget with high-speed Internet link (Monaghan, 2009; Gainsbury \& Wood, 2011).

Accessibility and the convenience of Internet gambling are the most usually reported importance of this style of gambling (Wood, Williams \& Lawton, 2007; Cotte \& Latour, 2009; McCormack \& Griffiths, 2012). Other importance commonly declared includes the alacrity and simplicity of Internet gambling, the comfortable ability to bet from one's residence, larger worth for fund which includes expenditure charge and additional benefits, increased number of gaming items and choices (Gainsbury, 2015).

Gainsbury and Wood (2011) are of the opinion that ease of access to Internet gambling particularly among savoir-faire school children may increase gambling and bring about rise in the occurrence of higgledy-piggledy gambling. These and a lot more have led several researchers to recommend that Internet gambling should be proscribed, or conversely synchronized (Watson, Liddell Jr, Moore \& Eshee Jr, 2004; Wood \& Williams, 2007; Adams, Sullivan, Horton, Menna \& Guilmett, 2007; Gainsbury \& Wood, 2011; Gainsbury, Parke \& Suhonen, 2013; Gainsbury, Russell, Hing, Wood, Lubman \& Blaszczynski, 2014).

Internet-facilitated gambling is different from terrestrial-based gambling mostly in terms of its steady availability, user-friendliness, concealed uninterrupted betting periods, enabled by the cooperative and accommodative Internet milieu (Monaghan, 2009; Wood, Williams \& Parke, 2012; Valentine \& Hughes, 2012; Gainsbury, Parke \& Suhonen, 2013; McCormack \& Griffiths, 2013; Gainsbury, Russell, Wood, Hing \& Blaszczynski, 2014). Also, the utilization of electronic forms of money such as bank transfer, e-wallet and credit cards increased the possibility of Internet gambling as gamblers have the mind-set of not expending actual money (Wood, Williams \& Lawton, 2007; Wood \& Williams, 2010; McCormack \& Griffiths, 2013; Hing, Gainsbury, Blaszczynski, Wood, Lubman \& Russell, 2014; GamCare, 2014).

The ease of access to Internet gambling may lead to development or aggravation of gambling disorder (Gainsbury \& Wood, 2011). Furthermore, gamblers are more likely to experience sleep disorder and distracted eating patterns (Siemens \& Kopp, 2011; Gainsbury, Parke \& Suhonen, 2013; Hing, Gainsbury, Blaszczynski, Wood, Lubman \& Russell, 2014). Gainsbury, (2015) opines that as there is increase in the recognition of Internet gambling, gamblers will prefer to adopt this mode in the future to boost their gambling career which may likely pose threat to their life. Several studies from different researchers have also found higher rates of health and mental disorders among Internet gamblers which affect their lives negatively (Wardle, Sproston, Orford, Erens, Griffiths, 2007; Petry, Weinstock, 2007; Griffiths, Wardle, Orford, Sproston, Erens, 2009; Lloyd, Doll, Hawton, Dutton, Geddes, Goodwin, Rogers, 2010b; Griffiths, Wardle, Orford, Sproston, Erens, 2011; LaPlante, Nelson, LaBrie, Shaffer, 2011; Wardle, Moody, Griffiths, Orford, Volberg, 2011; Jiménez-Murcia, Stinchfield, Fernández-Aranda, Santamaría, Penelo, Granero, Menchón, 2011; Kairouz, Paradis, Nadeau, 2012; McCormack \& Griffiths, 2012; . Hing, Cherney, Gainsbury, Lubman, Wood, Blaszczynski, 2014; LaPlante, Nelson, Gray, 2014).

In the opinion of Cabot (1999), gambling is seen as any activity in which an individual puts up valuable things or efforts for an unsure result in which the gambler has no power over. Internet gambling refers to gaming (casino style games) and wagering (racing and sports events) in the cyberspace. School children will prefer to gamble over 
the Internet than real life in the future because there is privacy. It can be accessed from anywhere in the world so far there is an Internet connection. There is also little, or no distracting factor and the atmosphere is not competitive. There are also a variety of payment options. Problems caused by Internet gambling include but are not limited to poverty, debts, thought of committing suicide, misdeed, depression, etc. (Ranade, Bailey \& Harvey, 2006).

\section{Conclusions}

The web is an immense tool for social and educational advancement. It is also full of probable perils. The chances of school children being exposed to these dangers increase without apposite parental support and guidance. Incontrovertibly, the web has positive as well as negative impacts in the society. Though the Internet enhances production of generations that are innovative, creative and think dynamically, a misuse of it will indisputably bring damage. The virtual community or the digital access becomes a precious asset to the youth and aged when good ethical practices in the usage of the Internet are sustained. It becomes a challenging experience for a parent once his or her child starts operating in the cyberspace. Therefore, parents should take quality and quick action to better manage and control Internet usage among their children to avoid social and health related problems. Also, government policies on education and culture should tackle the issue of abuse and other negative impacts of the Internet. Internet usage without close monitoring and appropriate supervision from parents, teachers and caregivers will affect school children negatively since it can either design or destroy the future of a child.

\section{Recommendations}

Cyber parenting is recommended for parents to actively supervise and monitor their children's online activities. Cyber parenting reflects the parenting skills and knowledge in the digital era.

Parents should be predominantly attentive to their children's Internet activities. They should not underestimate the amount of time their adolescents spend on the Internet and the extent of negative interactions present in this setting.

Parents need to equip themselves with the right knowledge and skills to guide their children in this digital era.

Parents should be actively involved in discussing their Internet experience children, sharing experiences of using the Internet, and closely monitoring and supervising their activities.

Parents should adopt the right digital parenting style.
They should act as mentors to their children as it will help them to develop healthy and balanced digital habit. Parents should not try to limit the children from having access to device and interactions on the Internet because of risks associated with technology. As a result of this, children whose parents limit their access to the Internet are the most likely to participate in inappropriate online activities whenever there is access. Also, parents should not freely allow their children without monitoring and supervising their activities.

Parents should be a part of their children's online activities by setting rules, communicating values, and acting as role models to their children. This is very important as their activities online are as important as their real-life activities. Once rules are set at their early lives and values are properly communicated, they will always live by them whether they are with their parents or not.

Parents should adopt parental control tools such as eKavach, angel child monitoring, safe browser etc. to supervise and monitor their children's online activities. This is suggested because it will be difficult for parents to keep a check on the personal devices of their children as the devices are in their control and they can easily overlook and hide the safety rules and also request privacy.

Researchers should develop community-based educational programmes for parents that are not born or brought up during the age of digital technology i.e. non digital natives. The community-based educational programmes should be implemented in the language of the parents' immediate environment to enable them understand in details the technicalities of children's engagements in the cyberspace. These community-based educational programmes are necessary to empower parents that are not good on technology to handle their children and be able to control their interactions in the cyberspace. Additionally, the community-based educational programmes would enable parents to recognize cyber-based activities involving their children that warrant the attention of law enforcement bodies i.e. cyber bullying.

\section{Acknowledgements}

I humbly wish to express my heartfelt appreciation to Dr. Daniel Ajayi at Technische Universitat Chemnitz, Germany who proof-read the draft of this article at no cost.

\section{Ethical Considerations}

This manuscript was written from ethical clearance UFS-HSD2019/1939. 


\section{Conflict of Interest}

The authors wish to respectfully declare that no conflicts of interest are in existence regarding this research.

\section{REFERENCES}

[1] Adams, G. R., Sullivan, A. M., Horton, K. D., Menna, R., and Guilmette, A. M. (2007). A study of differences in Canadian university students' gambling and proximity to a casino. Journal of Gambling Issues, 19, 9-18.

[2] Akbaba, S. \& Eroğlu, Y. (2013). İlköğretim öğrencilerinde siber zorbalık ve mağduriyetin yordayıcıları [The predictors of cyberbullying and cybervictimization in elementary school students]. Journal of Uludağ University Faculty of Education, 26(1), 105-121.

[3] Akbulut, Y., \& Çuhadar, C. (2011). Reflections of preservice information technology teachers regarding cyberbullying. Turkish Online Journal of Qualitative Inquiry, 2(3), 67-76.

[4] Aksaray, S. (2011) Siber Zorbalık. Ç.Ü. Sosyal Bilimler Enstitüsü Dergisi, Cilt 20, Sayı 2, 405-432.

[5] Arıcak, T., Siyahhan, S., Uzunhasanoglu, A., Sarıbeyoğlu, S., Çplak, S., Yılmaz, N., \& Memmedov, C. (2008). Cyberbullying among Turkish adolescents. Cyberpsychology \& Behavior, 11(3), 253-261.

[6] Badmus, B. G. (2018). Cyberspace abuse and the proliferation of poverty in Nigeria: Investigating the paradox of social-economic development. Africology: The Journal of Pan African Studies, 11(8) 33-46.

[7] Baker, C. K., \& Carren o, P. K. (2016). Understanding the role of technology in adolescent dating and dating violence. Journal of Child and Family Studies, 25, 308-320. https://doi.org/10.1007/s10826-015-0196-5.

[8] Borrajo, E., Gámez-Guadix, M., \& Calvete, E. (2015). Cyber dating abuse: Prevalence, context, and relationship with offline dating aggression. Psychological Reports, 116, 565-585. doi: 10.2466/21.16.PR0.116k22w4.

[9] Belsey, B. (2007). Cyberbullying: A real and growing threat. Alberta Teachers' Association Magazine, 88(1), 14-21.

[10] Best P, Manktelow R, Taylor B. (2014). Online communication, social media, and adolescent wellbeing: A systematic narrative review. Children and Youth Services Review, 41, 27-36.

[11] Brown, G., Maycock, B., \& Burns, S. (2005). Your picture is your bait: Use and meaning of cyberspace among gay men. Journal of Sex Research, 42(1), 63-73. doi:10.1080/00224490509552258.

[12] Bryant, R. (2001). Minerva - An Internet Journal of Philosophy, 5, 138-155.

[13] Bryant, K, and Sheldon, P. (2017). Cyber Dating in the Age of Mobile Apps: Understanding Motives, Attitudes, and Characteristics of Users. American Communication Journal,
$19(2), 1-15$.

[14] Bulut, Y., \& Alc1, B. (2014). Cyberbullying among secondary school students. Kalem International Journal of Education and Human Sciences, 4(2), 45-64.

[15] Burke, S. C., Wallen, M., Vail-Smith, K., \& Knox, D. (2011). Using technology to control intimate partners: An exploratory study of college undergraduates. Computers in Human Behavior, 27, 1162-1167. doi: 10.1016/j.chb.2010. 12.010.

[16] Cabot, N. A. (1999). The Internet gambling report ii: an evolving conflict between technology, policy \& law. Las Vegas: Trace.

[17] Calvete, E., Orue, I., Estévez, A., Villardón, L., \& Padilla, P. (2010). Cyberbullying in adolescents: Modalities and aggressors' profile. Computers in Human Behavior, 26(5), $1128-1135$

[18] Carnes, P. (2001). Out of the shadows: Understanding sexual addiction (3rd ed.). Center City, MN: Hazeldon.

[19] Cho, Y. K., \& Yoo, J. W. (2016). Cyberbullying, internet and SNS usage types, and perceived social support: A comparison of different age groups. Information, Communication \& Society, 20(10), 1-18.

[20] Corcoran, L., C. M. Guckin \& G. Prentice. (2015). Cyberbullying or Cyber Aggression? a Review of Existing Definitions of Cyber-Based Peer-to-Peer Aggression. Societies, 5, 245-255.

[21] Cotte, J. and Latour, K. A. (2009). Blackjack in the kitchen: Understanding online versus casino gambling. $J$ Consum Res., 35(5), 742-758.

[22] David-Ferdon, C., \& Hertz, M. F. (2007). Electronic media, violence, and adolescents: An emerging public health problem. Journal of Adolescent Health, 41, S1-S5. doi: 10.1016/j.jadohealth.2007.08.020.

[23] Doring, N. M. (2009). The Internet's impact on sexuality: A critical review of 15 years of research. Computers in Human Behavior, 25, 1089-1101. doi:10.1016/j.chb.2009.04.003.

[24] Draucker, C. B., \& Martsolf, D. S. (2010). The role of electronic communication technology in adolescent dating violence. Journal of Child and Adolescent Psychiatric Nursing, 23, 133-142. doi: 10.1111/j.1744-6171.2010.0023 5.x.

[25] Finkel, E. J., Eastwick, P. W., Karney, B. R., Reis, H. T., \& Sprecher, S. (2012). Online dating: A critical analysis from the perspective of psychological science. Psychological Science in the Public Interest, 13(1), 3-66. https://doi.org/10.1177/1529100612436522.

[26] Franc, E., Khazaal, Y., Jasiowka, K., Lepers, T., BianchiDemicheli, F., \& Rothen, S. (2018). Factor structure of the Cybersex Motives Questionnaire. Journal of Behavioral Addictions, 7(3), 601-609. doi: 10.1556/2006.7 .2018.67.

[27] Gainsbury, S. M. (2015). Online gambling addiction: the relationship between internet gambling and disordered gambling. Current Addiction Reports, 2(2), 185-193. DOI: 10.1007/s40429-015-0057-8.

[28] Gainsbury, S. and Wood, R. (2011). Internet gambling 
policy in critical comparative perspective: The effectiveness of existing regulatory frameworks. Internet Gambling Studies; 11, 309- 323.

[29] Gainsbury, S., Parke, J., and Suhonen, N. (2013). Attitudes towards Internet gambling: Perceptions of responsible gambling, consumer protection, and regulation of gambling sites. Computer Human Behavior, 29, 235-245.

[30] Gainsbury, S., Russell, A., Wood, R., Hing, N., and Blaszczynski, A. (2014). How risky is Internet gambling? A comparison of subgroups of Internet gamblers based on problem gambling status. New Media Soc. doi: $10.1177 / 1461444813518185$.

[31] Gainsbury, S., Russell, A., Hing, N., Wood, R., Lubman, D., and Blaszczynski, A. (2014). The prevalence and determinants of problem gambling in Australia: Assessing the impact of interactive gambling and new technologies. Psychology Addicted Behavior, 28(3), 769-779.

[32] GamCare (2014). Briefing paper: GamCare annual statistics 2013/14. Available from: http://www.gamcare.org.uk/news -and-media/publications/annual-reviewsandstatistics\#.VL7 vDUeUfwg.

[33] Good, B., and Fang, L. (2015). Promoting smart and safe internet use among children with neurodevelopment disorders and their parents. Clinical Social Work Journal, 43, 179-188 DOI 10.1007/s10615-015-0519-4.

[34] Griffiths, M. D., Wardle, H., Orford, J., Sproston, K., and Erens, B. (2009). Sociodemographic correlates of internet gambling: Findings from the 2007 British gambling prevalence survey. Cyberpsychol Behav. 12, 199-202.

[35] Griffiths, M., Wardle, H., Orford, J., Sproston, K., and Erens, B. (2011). Internet gambling, health, smoking and alcohol use: Findings from the 2007 British Gambling Prevalence Survey. Int J Ment Health Addict, 9, 1-11.

[36] Grubbs, J. B., Volk, F., Exline, J. J., \& Pargament, K. I. (2015). Internet pornography use: Perceived addiction, psychological distress, and the validation of a brief measure. Journal of Sex and Marital Therapy, 41(1), 83-106. doi:10.1080/0092623X.2013.842192.

[37] Hing, N., Cherney, L., Gainsbury, S., Lubman, D., Wood, R., and Blaszczynski, A. (2014). Maintaining and losing control during Internet gambling: A qualitative study of gamblers' experiences. New Media \& Society, 17, 1075-1095. DOI: 10.1177/1461444814521140.

[38] Hing, N., Gainsbury, S., Blaszczynski, A., Wood, R., Lubman, D., and Russell, A. (2014). Interactive Gambling. Report commissioned by Gambling Research Australia. Centre for Gambling Education \& Research, Southern Cross University. Available from: http://www.gamblingresearch.org.au/home/interactive+ga mbling+pdf.

[39] Hoff, D. L., \& Mitchell, S. N. (2009). Cyberbullying: Causes, effects, and remedies. Journal of Educational Administration, 47(5), 652-665.

[40] Jaishankar K., (2008). Space Transition Theory of Cyber Crimes. In Schmallager, F., \& Pittaro, M. (Eds.), Crimes of the Internet (pp.283-301). Upper Saddle River, NJ: Prentice Hall.
[41] Jiménez-Murcia, S., Stinchfield, R., Fernández-Aranda, F., Santamaría, J. J., Penelo, E., Granero, R., and Menchón, J. M. (2011). Are online pathological gamblers different from nononline pathological gamblers on demographics, gambling problem severity, psychopathology and personality characteristics? Int Gambl Stud., 11(3):325-337.

[42] Kairouz, S., Paradis, C., and Nadeau, L. (2012). Are online gamblers more at risk than offline gamblers? Cyberpsychol Behav Soc Netw. 15, 175-180.

[43] Koç, M., Horzum, M. B., Ayas, T., Aydın, F., Özbay, A., Uğur, E. \& Çolak, S. (2016). Sanal Zorbalıkla Baş Etme Ölçeği: Geçerlilik ve güvenirlik Çalışması [Coping With Cyberbullying Scale: Study of reliability and validity]. Sakarya University Journal of Education, 6(3), 116-128.

[44] LaPlante, D. A., Nelson, S. E., LaBrie, R. A., and Shaffer, H. J. (2011). Disordered gambling, type of gambling and gambling involvement in the British gambling prevalence survey 2007. Eur Journal of Public Health, 21, 532-7.

[45] LaPlante, D. A., Nelson, S. E., Gray, H. M. (2014). Breadth and depth involvement: Understanding Internet gambling involvement and its relationship to gambling problems. Psychol Addict Behav, 28, 396-403.

[46] Leisring, P. A., \& Giumetti, G. W. (2014). Sticks and stones may break my bones, but abusive text messages also hurt: Development and validation of the cyber psychological abuse scale. Partner Abuse, 5, 323-341. https://doi.org/10.1891/1946-6560.5.3.323.

[47] Lyndon, A., Bonds-Raacke, J., \& Cratty, A. D. (2011). College students' facebook stalking of ex-partners. Cyberpsychology, Behavior, and Social Networking, 14, 711-716. doi: 10.1089/cyber.2010.0588.

[48] Lloyd, J., Doll, H., Hawton, K., Dutton, W. H., Geddes, J. R., Goodwin, G. M., and Rogers, R. D. (2010b). How psychological symptoms relate to different motivations for gambling: An online study of internet gamblers. Biol Psychiat., 68(8), 733-740.

[49] McCormack, A. and Griffiths, M. D. (2012). Motivating and inhibiting factors in online gambling behaviour: A grounded theory study. International Journal of Mental Health Addiction 10(1), 39-53.

[50] McWilliams, S. \& Barrett, A. E. (2014). Online dating in middle and later life: Gendered expectations and experiences. Journal of Family Issues, 35(3), 411-36.

[51] Melander, L. A. (2010). College students' perceptions of intimate partner cyber harassment. Cyberpsychology, Behavior, and Social Networking, 13, 263-268. doi: 10.1089/cyber.2009.0221.

[52] Monaghan S. (2009). Responsible gambling strategies for Internet gambling: The theoretical and empirical base of using pop-up messages to encourage self-awareness. Computer Human Behavior, 25(1), 202-207.

[53] Niehuis, S. (2008). Dating and courtship. In J. T. Sears (Ed.), The Greenwood encyclopedia of love, courtship, and sexuality through history, The modern world 657-60. Westport, CT: Greenwood Press.

[54] Olweus, D. (1993). Bullying at school: What we know and what we can do. Cambridge, MA: Blackwell Publishers. 
[55] Patchin, J. W., \& Hinduja, S. (2006). Bullies move beyond the schoolyard a preliminary look at cyberbullying. Youth Violence and Juvenile Justice, 4(2), 148-169.

[56] Peskin, M. F., Markham, C. M., Shegog, R., Temple, J. R., Baumler, E. R., Addy, R. C., Emery, S. T. (2017). Prevalence and correlates of the perpetration of cyber dating abuse among early adolescents. Journal of Youth and Adolescence, 46, 358-375. doi: 10.1007/s10964-016-05681 .

[57] Petry, N. M, amd Weinstock J. (2007). Internet gambling is common in college students and associated with poor mental health. Am J Addiction, 16, 325-330.

[58] Ranade, S., Bailey, S. and Harvey, A. (2006). A literature review and survey of statistical sources on remote gambling. http://www.culture.gov.uk/nr/rdonlyres/e0a395c1-35cc-47 17-bf00-b1f6bd3a6b76/0/RemoteGambling rseReport.pdf.

[59] Reed, L. A., Tolman, R. M., \& Ward, L. M. (2016). Snooping and sexting: Digital media as a context for dating aggression and abuse among college students. Violence Against Women, 22, 1556-1576. doi: 10.1177/1077801216 630143.

[60] Ross, M.W., Tikkanen, R. \& Mansson, S. A. (2000). Differences between Internet samples and conventional samples of men who have sex with men: implications for research and HIV interventions. Social Science and Medicine, 51,749-758.

[61] Ross, M. W., Rosser, B. R. S., and Stanton, J. (2004). Beliefs about cybersex and Internetmediated sex of Latino men who have Internet sex with men: relationships with sexual practices in cybersex and in real life. Aids Care, 16(8) $1002-1011$.

[62] Şahin, M., Aydin, B., \& Sari, S. V. (2012). Cyber bullying, cyber victimization, and psychological symptoms: A study in adolescents. Çukurova University Faculty of Education Journal, 41(1), 53-59.

[63] Schenk, A. M., \& Fremouw, W. J. (2012). Prevalence, psychological impact, and coping of cyberbully victims among college students. Journal of School Violence, 11(1), 21-37.

[64] Schneider, S. K., O’donnell, L., Stueve, A., \& Coulter, R. W. (2012). Cyberbullying, school bullying, and psychological distress: a regional census of high school students. Am J Public Health, 102(1):171-177. doi:10.2105/AJPH.2011.300308.

[65] Shaughnessy, K., Byers, S., \& Thornton, S. J. (2011b). What is cybersex? Heterosexual students' definitions. International Journal of Sexual Health, 23(2), 79-89. doi:10.1080/19317611.2010.546945.

[66] Siemens, J. C., and Kopp, S. W. (2011). The influence of online gambling environments on self control. Journal of Public Policy Mark, 30:279-293.

[67] Slater, D. (2013). A Million First Dates How Online Dating Is Threatening Monogamy. Atlantic, 311(1), 40-46.

[68] Smith, P. K., Mahdavi, J., Carvalho, M., Fisher, S., Russell, S., \& Tippett, N. (2008). Cyberbullying: Its nature and impact in secondary school pupils. Journal of Child Psychology and Psychiatry, 49(4), 376-385.
[69] Stewart, G. (2015). Dating apps vs dating sites: 10 questions to ask yourself. DatingAdvice.com. Retrieved fromhttp://www.datingadvice.com/online-dating/dating-ap ps-vs-dating-sites.

[70] Suler, J. (2005). The Psychology of Cyberspace. Retrieved on March 15, 2017 fromhttp://users.rider.edu/ suler/psycy ber/psychspace.html.

[71] Surry, D. W., \& Farquhar, J. D. (1997). Diffusion theory and instructional technology. Journal of Instructional Science and Technology, 2(1), 24-36.

[72] Topçu, Ç. (2014). Modeling the relationships among coping strategies, emotion regulation, rumination, and perceived social support in victims of cyber and traditional bullying (Doctoral dissertation). Retrieved from http://etd.lib.metu. edu.tr/upload/12618232/index.pdf

[73] Tsimtsiou, Z., Haidich, A. B., Kokkali, S., Dardavesis, T., Young, K. S., \& Arvanitidou, M. (2014). Greek version of the Internet Addiction Test: A validation study. The Psychiatric Quarterly, 85(2), 187-195.doi:10.1007/s11126 -013-9282-2.

[74] Twohig, M. P., Crosby, J. M., \& Cox, J. M. (2009). Viewing Internet pornography: For whom is it problematic, how, and why? Sexual Addiction \& Compulsivity, 16(4), 253-266. doi:10.1080/10720160903300788.

[75] Valentine, G., and Hughes, K. (2012). Shared space, distant lives? Understanding family and intimacy at home through the lens of internet gambling. T I Brit Geogr. 37(2), 242-255.

[76] Vandeweerd, C., Myers, J., Coulter, M., Yalcin, A., \& Corvin, J. (2016). Positives and negatives of online dating according to women 50+. Journal of Women \& Aging, 28(3), 259-270.

[77] Wardle, H., Moody, A., Griffiths, M., Orford, J., and Volberg, R. (2011). Defining the online gambler and patterns of behaviour integration: Evidence from the British Gambling Prevalence Survey. International Gambling Studies, 11(3), 339-356.

[78] Watson, S., Liddell, Jr P., Moore, R. S., Eshee, Jr W. D. (2004). The legalization of Internet gambling: a consumer protection perspective. Journal Public Policy Mark, 23(2), 209- 213.

[79] Wéry, A., \& Billieux, J. (2017). Problematic cybersex: Conceptualization, assessment, and treatment. Addictive Behaviors, 64, 238-246. doi:10.1016/j.addbeh.2015.11.007.

[80] Wood, R. T., and Williams, R. J. (2007). Problem gambling on the Internet: Implications for Internet gambling policy in North America. New Media Soc. 9(3), 520-542.

[81] Wood, R. T., Williams, R. J., and Lawton, P. K. (2007). Why do Internet gamblers prefer online versus land-based venues? Some preliminary findings and implications. Journal of Gambling Issues, 20, 235-252.

[82] Wood, R. T., Williams, R. J., and Parke, J. (2012). The relationship between Internet gambling and problem gambling. In R. J. Williams, R.T. Wood., \& J. Parke (Eds.) Routledge Handbook on Internet Gambling, Oxon, UK; 200-212. 
[83] Young, K. S., Griffin-Shelley, E., Cooper, A., O'mara, J., \& Buchanan, J. (2000). Online infidelity: A new dimension in couple relationships with implications for evaluation and treatment. Sexual Addiction \& Compulsivity: The Journal of Treatment and Prevention, 7(1-2), 59-74. doi: 10.1080/10720160008400207.

[84] Zweig, J. M., Lachman, P., Yahner, J., \& Dank, M. (2014). Correlates of cyber dating abuse among teens. Journal of Youth and Adolescence, 43, 1306-1321. https://doi.org/10. 1007/s10964-013-0047-x.

[85] Lee, S. \& Chun, J.S. (2020). Conceptualizing the impacts of cyberbullying victimization among Korean male adolescents. Children and Youth Services Review, 117, https://doi.org/10.1016/j.childyouth.2020.105275.
[86] AnKee, A.W. \& Yazdanifard, R. (2015). The review of the ugly truth and negative aspects of online dating. Global Journal of Management and Business Research, XV(IV), 1-7.https://globaljournals.org/GJMBR_Volume15/5-The-R eview-of-the-Ugly.pdf

[87] Lancaster, M., Seibert, G.S., Cooper, A.N., May, R.W., \& Fincham, F. (2020). Relationship in the context of cyber dating abuse: The role of attachment. Journal of Family Issues, 41(6), 739-758. https://doi.org/10.1177/0192513X1 9881674

[88] Ige, O.A. School-based cybersecurity education programme for schoolchildren in South Africa! A timely call from Bloemfontein. Universal Journal of Educational Research 8(6), 2710-2716, DOI: 10.13189/ujer.2020.080656 